\title{
Endoscopic Removal of Sharp-Pointed Foreign Bodies with Both Sides Embedded into the Duodenal Wall in Adults: A Retrospective Cohort Study
}

\author{
Meihong Yu (iD) ${ }^{1,2}$ \\ Kaixuan $\mathrm{Li}\left(\mathbb{D}^{3}\right.$ \\ Shishuang Zhou ${ }^{4}$ \\ Hanyu Wang ${ }^{1,2}$ \\ Meixian Le ${ }^{1,2}$ \\ Chen $\mathrm{Li}^{1,2}$ \\ Deliang Liu (iD) ${ }^{1,2}$ \\ Yuyong Tan (iD) ${ }^{1,2}$
}

'Department of Gastroenterology, The Second Xiangya Hospital, Central South University, Changsha, Hunan, 4I00II, People's Republic of China; ${ }^{2}$ Research Center of Digestive Disease, Central South University, Changsha, Hunan, 4I00II, People's Republic of China; ${ }^{3}$ Department of Urology, Xiangya Hospital, Central South University, Changsha, Hunan, 4l0008, People's Republic of China; ${ }^{4}$ Department of Nursing Administration, Army Military Medical University, Chongqing, 400038, People's Republic of China

Correspondence: Yuyong Tan Department of Gastroenterology, The Second Xiangya Hospital, Central South University, No. 139 Middle Renmin Road, Changsha, Hunan, 4I00II, People's

Republic of China

Tel +86- I5 I I628062I

Fax +86-73I-85533525

Email tanyuyong@csu.edu.cn

Kaixuan $\mathrm{Li}$

Department of Urology, Xiangya Hospital, Central South University, Changsha,

Hunan, 410008, People's Republic of

China

Tel +86 I5580027242

Email lkxxgz@csu.edu.cn
Purpose: Sharp-pointed FBs with both sides embedded in the duodenal wall are rare. Compared with smooth edged FBs, sharp objects are more likely to be associated with significant adverse events, when penetrating the wall of the digestive tract. The clinical features of patients who experienced sharp-pointed FBs embedded in both sides of the duodenum were retrospectively analyzed, as were the efficacy and safety of endoscopic removal of these FBs.

Patients and Methods: This retrospective study included 21 adults with both sides of sharp-pointed FBs embedded into the duodenal wall who were admitted to the Second Xiangya Hospital in China between January 1, 1996, and May 31, 2021. Data associated with the endoscopic removal of these FBs were collected from the electronic medical record system (EMRS) of the hospital.

Results: The incidence rate of duodenal total FBs and FBs embedded in both sides was $8.87 \%$ and $1.03 \%$, respectively. The success rate of endoscopic treatment was $100.00 \%$ in 124 patients without embedded duodenal FBs and $97.14 \%$ in 35 patients with one side embedded duodenal FBs. Of the 21 patients with FBs embedded in both sides of the duodenal wall, endoscopic removal was successful in $85.71 \%$ of patients, whereas $14.29 \%$ required surgery. FBs removed from these patients included toothpicks in 12; needles in 3; jujube pits in 2; and a chopstick, dentures, fish bones, and chicken bones in one each. Most of these 21 FBs were located in the bulb and descending duodenum, followed by the third part of duodenum.

Conclusion: Sharp-edged FBs with both sides embedded in the duodenal wall are rare. Endoscopic removal may be considered as a feasible, safe, and effective method of removing sharp-pointed FBs with both sides embedded in the duodenal wall. And if endoscopic removal is unsuccessful, surgical management can be a secondary option.

Keywords: adult, duodenum, endoscopic removal, foreign bodies, surgical operation

\section{Introduction}

Foreign body (FB) ingestion can be defined as the accidental or intentional swallowing of objects, or as the natural swallowing of materials when taking medication or food. ${ }^{1}$ FB ingestion mainly occurs in children, which is a potentially lifethreatening and common problem, although it is occasionally observed in adults. ${ }^{2}$ Most accidentally ingested FBs pass through the digestive tract without any complications and rarely require intervention, and the FBs accidentally ingested are 
usually fish bones, bones of other animals, and dentures. ${ }^{3}$ FB ingestion is commonly encountered in clinical practice, with the number of these patients increasing in Asia. ${ }^{4,5}$ Although most FBs pass through the gastrointestinal tract spontaneously, endoscopic or even surgical interventions may be required. ${ }^{6-8}$

The anatomical morphology of the duodenum includes angulation, a $\mathrm{C}$ loop shape, thin wall, and complex adjacent organs. Thus, FB ingestion in the duodenum is regarded as a special situation and FBs in the duodenum are associated with a higher rate of failure of endoscopic removal. ${ }^{9}$ Compared with smooth edged FBs, sharp objects are more likely to be associated with significant adverse events, including mucosal ulceration, abscess, peritonitis, or fistula formation, when penetrating the wall of the digestive tract. ${ }^{10}$ Sharp-pointed objects lodged in the duodenum, especially objects with both sides embedded in the duodenal wall, may be more challenging to remove, likely due to the anatomical morphology of the duodenum. The third portion of duodenum is fixed to the retroperitoneum, consequently, the surgical approach may be limited by an insufficient view field to treat mesocolon with the mesenteric vessels. ${ }^{11}$ Compared with surgical removal, endoscopic removal of FBs is associated with a lower probability of adverse events and less trauma and bleeding. ${ }^{9,12,13}$

To our knowledge, few studies to date have reported the outcome of endoscopic removal of FBs embedded in both two sides of the duodenum. Although European Society of Gastrointestinal Endoscopy (ESGE) provides guideline for removal of FBs in the upper gastrointestinal tract in adults, the qualities of many evidence are low. ${ }^{8}$ The present study therefore retrospectively analyzed the effectiveness and safety of endoscopic removal of these sharp-pointed FBs from patients in a tertiary hospital in China.

\section{Materials and Methods}

\section{Patients}

The medical records of the Second Xiangya Hospital were reviewed to identify adults who had been admitted to this hospital for gastrointestinal FBs ingestion, as confirmed endoscopically or radiographically, between January 1, 1996, and May 31, 2021. Patients were included if they were diagnosed with both sides of an FB embedded in the duodenal wall. Patients were excluded if (I) the FB was located in any part of the digestive tract other than the duodenum, or (II) if the FB was not embedded or only one side was embedded into the duodenal wall, or the patient was younger than 18 years old. In the present study, we combined the patients' complaints, imaging findings and endoscopic findings to define that FBs were sharp and bilaterally embedded in the duodenal wall. 5 patients had transmural lesions but none of these cases had preoperative perforations or critical conditions requiring emergency surgery. All procedures followed were in accordance with the ethical standards of the responsible committee on human experimentation (institutional and national) and with the Helsinki Declaration of 1975. The study protocol was approved by the institutional ethics committee of the Second Xiangya Hospital (NO. LY2020124).

\section{Surgical Procedure}

All patients provided written informed consent before endoscopic or surgical treatment. Endoscopic removal (Gastroscopy, GIF XQ240/Q260/HQ290, Olympus) was performed under conscious sedation with a transparent cap attached. A FB grasping forceps, such as a rat-tooth or alligator-tooth forceps, was used to grasp the end of the $\mathrm{FB}$, and the longitudinal axis of the FB parallel to the longitudinal axis of the gastrointestinal cavity. No fluoroscopy was used for procedure. After removing the FBs, routine endoscopy was performed to determine whether the mucosa was damaged and, if so, the extent of the damage. The wound surface was managed using routine procedures.

\section{Data Collection}

All data were collected from the electronic medical record system (EMRS) of the Second Xiangya Hospital. Patients' demographic and clinical characteristics were recorded, including age; sex; any associated disease; history of FB ingestion; time from FB ingestion to removal; symptoms; FB location; endoscopic findings at the embedded sides; types and features of FBs; and adverse events, defined as any injury caused by the FBs or any endoscopic procedure during the manipulation of FBs. ${ }^{14}$

\section{Statistical Analysis}

All statistical analyses were descriptive statistics, performed using SAS version 9.3 (SAS Institute Inc., Cary, NC, USA). Data are presented as number (\%) or as mean \pm standard deviation (SD) necessary. 


\section{Results}

Between January 1, 1996, and May 31, 2021, 2030 adults were admitted to the Second Xiangya Hospital for gastrointestinal FBs ingestion, as confirmed endoscopically or radiographically. Of the 2030 patients, 1850 (91.13\%) were excluded because their FBs were located outside the duodenum, including 1432 (70.54\%) in the esophagus, $327(16.11 \%)$ in the stomach, $70(3.45 \%)$ in the colon and rectum, and $21(1.03 \%)$ in the intestines. Of the remaining 180 patients with FBs in the duodenum, 159 (88.33\%) were excluded, 124 (68.89\%) because their FBs were not embedded and 35 (19.44\%) because their FBs were embedded in only one side (Figure 1). Therefore, the incidence rate of duodenal FBs was 8.87\% (180/2030), and the incidence rate of duodenal FBs embedded on both sides was $1.03 \%(21 / 2030)$.

Of the 21 patients with embedded duodenal FBs, 17 $(80.95 \%)$ were men and $4(19.05 \%)$ were women. Among them, $5(23.81 \%)$ were aged $18-40$ and $40-50$ years respectively, $8(38.10 \%)$ were aged $>60$ years, whereas only $3(14.29 \%)$ were aged 51-60 years. Fourteen $(66.67 \%)$ patients realized that they had ingested these FBs. Although one patient had schizophrenia, most of these patients were not mentally ill. The time between

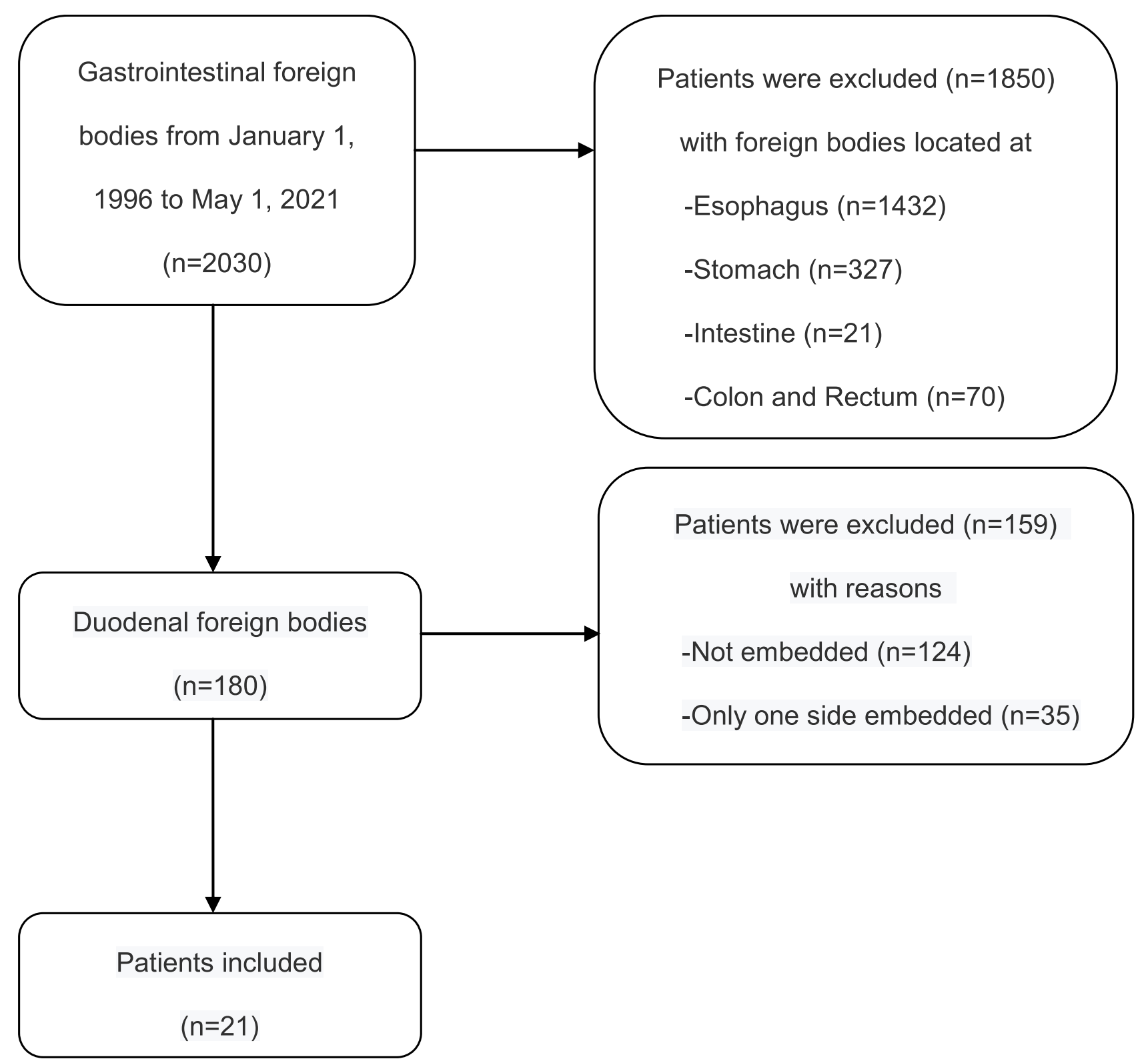

Figure I Flowchart of patient selection. 
FBs ingestion and removal generally ranged from 1 to 3 days due to the necessary examinations after admission. Most of these FBs embedded in both sides were located in the bulb and descending duodenum, followed by the third part of duodenum. Mucosal redness was the most frequent injury caused by these sharp-pointed FBs.

Endoscopic removal of these FBs was successful in $18(85.71 \%)$ of these patients, with the other $3(14.28 \%)$ requiring open surgery. The success rate of endoscopic removal was lower than those FBs not embedded (124/ $124,100.00 \%)$ or with only one side embedded $(34 / 35$, $97.14 \%$ ). Of these 3 patients requiring open surgeries, one had dentures embedded in the third part of duodenum, as determined during endoscopic treatment. This object, however, was solid and firmly embedded in the wall of the duodenum, make it difficult to remove by endoscopic methods. The other two patients were in generally poor conditions. Therefore, endoscopic removal was not attempted. Subsequent gastroscopy and follow-up showed no evidence of adverse events in any of these 21 patients (Table 1).

All patients underwent a thorough preoperative evaluation before endoscopic surgery, using the procedure shown in Figure 2. Most of the patients were symptomatic, with $10(47.62 \%)$ having abdominal pain, $2(9.52 \%)$ each having abdominal discomfort and fever, and one (4.76\%) each having melena and right iliac fossa pain. Abdominal discomfort indicated symptoms that were difficult to describe, but different from the patients' sense of a normal abdomen. Interestingly, a patient admitted with a main complaint of "right iliac fossa pain" was found by computed tomography (CT) to have a chopstick embedded in the duodenum (Table 2).

The most common type of foreign objects was a toothpick, observed in 12 (57.14\%) patients, followed by a needle in $3(14.29 \%)$, a jujube pit in $2(9.52 \%)$, a chopstick in one $(4.76 \%)$, dentures in one $(4.76 \%)$, and animal bones in $2(9.52 \%)$, one each with fish bones and chicken bones. The mean length of the embedded FBs was $5.66 \pm 1.73 \mathrm{~cm}$, with the chopstick being the longest, about $10.00 \mathrm{~cm}$, the toothpicks averaging $6.62 \pm$ $0.24 \mathrm{~cm}$, and the other FBs ranging from all 3.00$4.00 \mathrm{~cm}$ (Table 3). Sample FBs with both sides embedded into the duodenal wall are shown in Figure 3. Most of these FBs were sharp and could easily damage the mucous membranes of the duodenum. However, 5 patients had transmural lesions but none of
Table I Baseline Characteristics of Patients

\begin{tabular}{|c|c|}
\hline Characteristics & $\begin{array}{l}\text { No./Total } \\
\text { (\%) }\end{array}$ \\
\hline \multicolumn{2}{|l|}{ Age } \\
\hline $18-40$ & $5 / 2 I(23.81)$ \\
\hline $4 I-50$ & $5 / 21(23.81)$ \\
\hline $5 I-60$ & $3 / 21$ (14.29) \\
\hline$>61$ & $8 / 21(38.10)$ \\
\hline \multicolumn{2}{|l|}{ Gender } \\
\hline Male & $|7 / 2|(80.95)$ \\
\hline Female & $4 / 21(19.05)$ \\
\hline \multicolumn{2}{|l|}{ Associated disease } \\
\hline Duodenal diverticulum & $2 / 21(9.52)$ \\
\hline Schizophrenia & $|/ 2|(4.76)$ \\
\hline Bed-ridden & $2 / 21(9.52)$ \\
\hline Duodenal polyp & $\mathrm{I} / 2 \mathrm{I}(4.76)$ \\
\hline \multicolumn{2}{|l|}{ History of FB ingestion } \\
\hline Yes & $|4 / 2|(66.67)$ \\
\hline Unclear & $7 / 21$ (33.33) \\
\hline \multicolumn{2}{|l|}{ Duration between ingestion and removal (day) } \\
\hline$<$ I day & $3 / 21(14.29)$ \\
\hline I-3 days & $\mid \mathrm{I} / 2 \mathrm{I}(52.38)$ \\
\hline$>3$ days & $7 / 21$ (33.33) \\
\hline \multicolumn{2}{|l|}{ Location } \\
\hline $\begin{array}{l}\text { One side in bulb, the other in descending } \\
\text { duodenum }\end{array}$ & $\mathrm{I} / 2 \mathrm{I}(4.76)$ \\
\hline Descending duodenum & $7 / 21(33.33)$ \\
\hline Bulb & $8 / 21(38.10)$ \\
\hline Third part of duodenum & $5 / 2 I(23.8 I)$ \\
\hline \multicolumn{2}{|l|}{ Endoscopic finding at embedded sides } \\
\hline Mucosal redness & $\mid \mathrm{I} / 2 \mathrm{I}(52.38)$ \\
\hline Minor oozing & $\mathrm{I} / 2 \mathrm{I}(4.76)$ \\
\hline Mucosal swelling & $2 / 21(9.52)$ \\
\hline Mucosal erosion & $\mathrm{I} / 2 \mathrm{I}(4.76)$ \\
\hline Ulcer & $3 / 21$ (14.29) \\
\hline Mucosal laceration & $\mathrm{I} / 2 \mathrm{I}(4.76)$ \\
\hline \multicolumn{2}{|l|}{ Postoperative evaluation } \\
\hline Success rate & $|8 / 2|(85.7 \mid)$ \\
\hline Adverse events & $0 / 21(0.00)$ \\
\hline Overall & $21(100.00)$ \\
\hline
\end{tabular}

Abbreviation: FB, foreign bodies.

these cases had preoperative perforations. Preoperative plain radiography detected embedded objects in 15 $(71.43 \%)$ patients, but yielded false-negative results in the other $6(28.57 \%)$, including 3 with toothpicks and one each with dentures, fish bones and chicken bones (Table 4). 


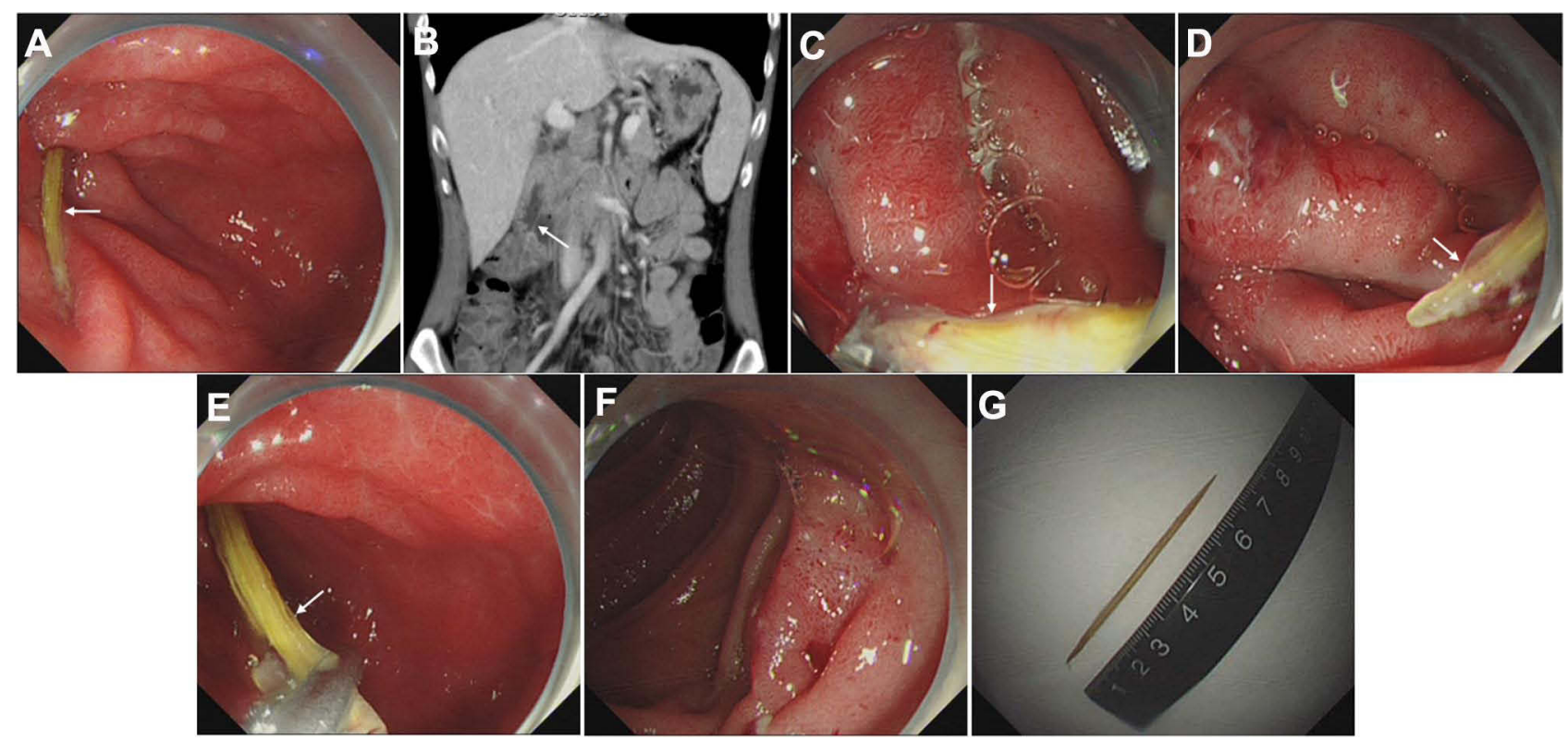

Figure 2 Case illustration of endoscopic removal of a toothpick. (A) Endoscopic image showing impaction of a toothpick in the descending duodenum. (B) Computerized tomography showing the toothpick. (C) Extraction of one side of the toothpick using grasping forceps. (D) Exposure of one side of the toothpick, and we could see the wound surface impacted. (E) Extraction of the other side of the toothpick. (F) Oozing of the wound surface after extraction of the toothpick. (G) The extracted toothpick. The white arrow points to FBs.

Eighteen patients with bilateral FBs embedded into the duodenal wall were successfully removed under endoscopy. Only mild intestinal mucosal injury and a small amount of bleeding were observed in these 18 patients after endoscopic removal of FBs. No subcutaneous and mediastinal emphysema, perforation, delayed postoperative bleeding and FBs-related death occurred in these patients during the 12-month follow-up period.

\section{Discussion}

FBs in the gastrointestinal tract occurs predominantly in patients with mental disorders and in children aged 6 months to 6 years. ${ }^{15}$ Although over $80.0 \%$ FBs in the gastrointestinal tract pass spontaneously, $10-20 \%$ of these patients require endoscopic removal and about $1 \%$ require surgery. ${ }^{16} \mathrm{FBs}$ are less frequent in the duodenum than in the esophagus and stomach, with only $8.87 \%$ of all adults who presented with gastrointestinal FBs in our institution having FBs in the duodenum. Very few patients have sharp-edged FBs with both sides embedded in the duodenal wall, and few studies to date have evaluated these patients. This study therefore evaluated the overall characteristics of FBs with both sides embedded in the duodenal wall and assessed the effectiveness and safety of their endoscopic removal in a tertiary hospital for a period over 25 years.
In our study, endoscopic removal of sharp-pointed FBs with both sides embedded in the duodenal wall was successful in $85.71 \%$ of patients. However, the success rate of endoscopic treatment was $100.00 \%$ in 124 patients without embedded duodenal FBs and $97.14 \%$ in 35 patients with one-side embedded duodenal FBs. The only failed case of endoscopic removal of one-side embedded duodenal FBs was a chopstick, which was too long in size and had perforated into the liver to form liver abscess. Thus, the endoscopic removal of sharp-pointed FBs with both sides embedded into the duodenal wall seems more difficult. In addition, the success rate of removing upper gastrointestinal FBs under endoscopy is generally more than $90 \%$, even up to $96.0 \%,{ }^{17,18}$ which was higher than that in our

Table 2 Symptoms Associated with Both Sides Embedded into Duodenal Wall

\begin{tabular}{|l|l|}
\hline Symptoms & No./Total (\%) \\
\hline Abdominal pain & $10 / 2 \mathrm{I}(47.62)$ \\
Abdominal discomfort & $2 / 2 \mathrm{I}(9.52)$ \\
Fever & $2 / 2 \mathrm{I}(9.52)$ \\
Melena & $\mathrm{I} / 2 \mathrm{I}(4.76)$ \\
Right iliac fossa pain & $\mathrm{I} / 2 \mathrm{I}(4.76)$ \\
Asymptomatic & $5 / 2 \mathrm{I}(23.8 \mathrm{I})$ \\
\hline Overall & $2 \mathrm{I}(\mathrm{I00.00)}$ \\
\hline
\end{tabular}


Table 3 Characteristics of FB Which Were Both Sides Embedded into Duodenal Wall

\begin{tabular}{|l|l|l|}
\hline Types of FB & Length $(\mathrm{cm})$ & No./Total (\%) \\
\hline Toothpick & $6.62 \pm 0.24$ & $\mathrm{I} / 2 \mathrm{I}(57.14)$ \\
Jujube pit & 3.50 & $2 / 2 \mathrm{I}(9.52)$ \\
Chopstick & 10.00 & $\mathrm{I} / 2 \mathrm{I}(4.76)$ \\
Needle & $3.83 \pm 0.29$ & $3 / 2 \mathrm{I} \mathrm{(I4.29)}$ \\
Denture & 4.00 & $\mathrm{I} / 2 \mathrm{I} \mathrm{(4.76)}$ \\
Fish bones & 4.00 & $\mathrm{I} / 2 \mathrm{I} \mathrm{(4.76)}$ \\
Chicken bones & 3.00 & $\mathrm{I} / 2 \mathrm{I} \mathrm{(4.76)}$ \\
Overall & $5.66 \pm \mathrm{I} .73$ & $2 \mathrm{I} / 2 \mathrm{I}(\mathrm{I00.00)}$ \\
\hline
\end{tabular}

Abbreviation: FB, foreign bodies.

study. This is likely to be related to the unique anatomical location of the duodenum, especially the third part, which is fixed to the retroperitoneum. Surgical approach to retroperitoneal duodenum is more limited because of its deep location and view field. ${ }^{11}$

Compared with the sharp-pointed FBs with both sides embedded into the duodenal wall, the removal process of one-side embedded duodenal FBs is easier because this removal has more space to pull the FBs out without fear of injuring the contralateral duodenum. ${ }^{19}$ It also makes the duodenal wall less likely to perforate and bleed. So the patients' intake history, preoperative imaging and endoscopic findings should be examined carefully to better identify the location of the FBs and whether it is embedded.

This study found that the age distribution of these patients was relatively even, with the proportion of older people being slightly higher. Similar to previous findings, most of these patients were men. ${ }^{20}$ Of the 21 patients, 7 were unaware that they had ingested FBs, although and only one had schizophrenia. However, 12 of the 21 FBs were small toothpicks. Indeed, $54 \%$ of patients with accidental toothpick ingestion were unaware that they had ingested these FBs, with about $23 \%$ of these toothpicks being located in the duodenum. ${ }^{21}$

Most of the embedded FBs in the present study were found in the descending duodenum and bulb, the first and second parts of the duodenum. The wall of the duodenal bulb are thin, with the bulb turning into the descending part of the duodenum at the back and lower parts of the gallbladder neck. The turning part forms an upward curve of the duodenum. The descending part of the duodenum and the horizontal part continue to form a curved downward curve at right angles. The duodenal wall are a smooth muscle structure with an inner ring and an outer longitudinal area. Thus, the horizontal and vertical elasticity of the duodenum is very poor, and the expansion space very small. The duodenum requires peristalsis to push the intestinal contents. Therefore, FBs can easily become embedded in the bulb and the descending and horizontal parts of the duodenum.

Injuries caused by FBs, such as mucosal redness and ulcer, can occur, and also can cause serious adverse events after endoscopic removal. Endoscopic removal was successful in $18(85.71 \%)$ of the 21 patients, with none experiencing any adverse events, such as digestive tract bleeding, perforation, obstruction, and damage to nearby organs. Because surgical intervention involving the duodenum is more invasive and expensive, with slower recovery, endoscopic removal is usually attempted first. Although studies have indicated the need to consider surgical removal for FBs with sharp points, ${ }^{22}$ case reports have described the successful
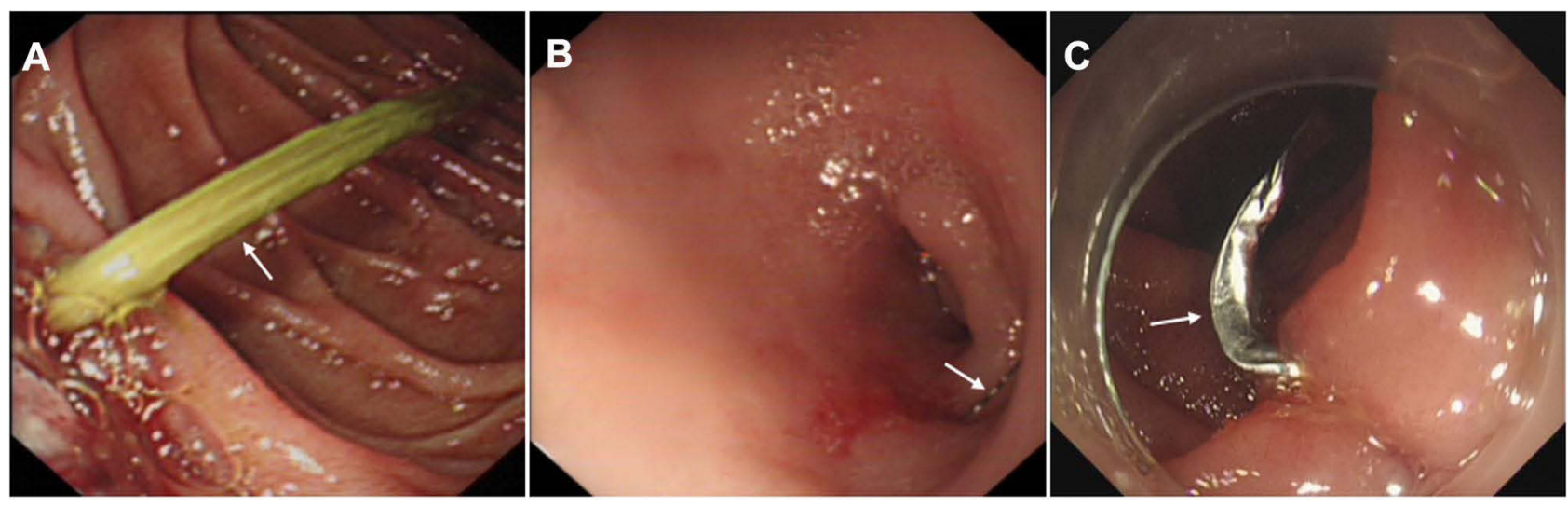

Figure $3 \mathrm{FBs}$ examples which were both sides embedded into the duodenal wall. (A) Impaction of a toothpick in the descending duodenum. (B) Impaction of a needle in the bulb. (C) Impaction of a denture in the descending duodenum. The white arrow points to FBs. 
Table 4 Comparison of Radiologic Signs Between Different FBs

\begin{tabular}{|l|l|l|l|l|l|l|l|}
\hline Radiologic & Toothpick & Jujube Pit & Needle & Denture & Fish Bones & Chopstick & Chicken Bones \\
\hline Positive (\%) & $9(42.86)$ & $2(9.52)$ & $3(14.29)$ & 0 & 0 & I (4.76) & 0 \\
\hline Negative (\%) & $3(14.29)$ & 0 & 0 & I (4.76) & I (4.76) & 0 & I (4.76) \\
\hline Total (\%) & I (57.14) & $2(9.52)$ & $3(14.29)$ & I (4.76) & I (4.76) & I (4.76) & I (4.76) \\
\hline
\end{tabular}

endoscopic removal of sharp-pointed FBs, such as multiple sharp gastro-duodenal needles, ${ }^{23}$ a barbecue grill cleaning brush, ${ }^{24}$ the temple of a pair of glasses, ${ }^{25}$ a biliary stent, ${ }^{26}$ a lollipop stick, ${ }^{27}$ a sewing needle, ${ }^{28}$ fish bones, ${ }^{29}$ and a large FB $>10 \mathrm{~cm}^{30}$ The mean length of the FBs in the present study was $5.66 \pm 1.73 \mathrm{~cm}$, making endoscope removal the first choice.

FB impaction lasting more than 24 hours has been reported to significantly increase the incidence of adverse events. ${ }^{31}$ Moreover, if not removed properly, ${ }^{32}$ sharp FBs that penetrate the duodenal wall can cause serious adverse events, such as gastrointestinal bleeding, peritonitis, duodenal perforation, hepatic abscess, and injury to adjacent organs or vessels, requiring urgent or emergent intervention. ${ }^{33-37}$ Most of the patients (18/ $21,85.71 \%$ ) in the present study underwent an endoscopic procedure for FB removal more than 1 day after ingestion, but none experienced obvious adverse events after treatment. Because the duodenum is a $\mathrm{C}$-shaped organ, sharp objects may more easily penetrate the duodenal wall, indicating that FBs should be removed within 24 hours of ingestion.

Patients who experienced FBs perforation of the duodenal wall were reported to feel no discomfort. ${ }^{22}$ Although small bowel perforation has been found to cause acute symptoms, duodenal penetration by FBs usually induces chronic inflammation, such as pyrexia of unknown origin, abdominal mass, and abscess collection. ${ }^{38}$ Therefore, it was not surprising that many of our patients were asymptomatic. Moreover, some FBs were missed by X-rays, mainly because these FBs were wrapped in the mucous membranes of the digestive tract, with covering by mucosal edema obscuring the FBs. In addition, some FBs do not show ultrasound shadows, resulting in a missed diagnosis. ${ }^{39} \mathrm{CT}$ has been shown to be the optimal modality for identifying early stage FBs, as CT can accurately determine the location of the ends and depths of the FBs. ${ }^{40}$ In addition, endoscopy can be used as a diagnostic tool, as well as for treatment.
Successful removal of FBs embedded in the duodenum should include preoperative radiographic assessment. CT is optimal, as it can accurately determine the location of both ends of the FB, the depth of duodenal penetration, and the absence of injury to vessels or adjacent organs. If vessel penetration is observed, endoscopic removal is contraindicated. During endoscopic examination, the patient's position should be altered to expose the FB. A transparent cap should be attached and the FB grasped at its end and kept parallel to the longitudinal axis of the gastrointestinal tract to reduce unintentional injury to the gastrointestinal mucosa; overtubes may also be helpful. ${ }^{41}$ In addition, the relationship of the FB with adjacent vessels and organs we should be evaluated, as should the severity of local ulcers. To avoid injury to these vessels and organ, the end of the FB closest to these vessels or organs should be removed first. If both ends do not involve vessels or organs, the end with more severe inflammation or deeper ulcer should be removed first. ${ }^{42}$ Adequate postoperative management is also necessary, with endoscopic clips used in patients with bleeding, perforation, or fistula. Treatments with proton pump inhibitors and antibiotics have been recommended. Of the 21 patients in the present study, 18 underwent successful FB removal endoscopically without severe adverse events. In addition, although endoscopic retrieval of FBs located in the first and second portions of the duodenum is easier, endoscopic removal is also suitable for other parts of the duodenum. ${ }^{43}$

This study had several limitations. Specifically, this study was a single center, retrospective analysis of only 21 patients enrolled over 25 years, which may have resulted in selection retrospective bias. Despite these limitations, this study to our knowledge is the first comprehensive assessment of FBs with both sides embedded into duodenal wall. The results of this analysis indicate that endoscopic treatment should be the treatment of choice, as it is both safe and effective. 


\section{Conclusion}

Sharp-edged FBs with both sides embedded in the duodenal wall are rare. Endoscopic removal may be considered as a feasible, safe, and effective method of removing sharp-pointed FBs with both sides embedded in the duodenal wall. And if endoscopic removal is unsuccessful, surgical management can be a secondary option.

\section{Acknowledgments}

The authors thank the patients for their support. This work was supported by the Key Research Project of Hunan Province (grant number 2018SK21311).

\section{Disclosure}

None of the authors has any conflicts of interest to report.

\section{References}

1. Hong K, Kim Y, Kim J, et al. Risk factors for complications associated with upper gastrointestinal foreign bodies. World $J$ Gastroenterol. 2015;21(26):8125-8131. doi:10.3748/wjg.v21.i26.8125

2. Mathew RP, Liang TI, Kabeer A, et al. Clinical presentation, diagnosis and management of aerodigestive tract foreign bodies in the paediatric population: part 2. SA J Radiol. 2021;25:2027. doi:10.4102/sajr.v25i1.2027

3. Mathew RP, Sarasamma S, Jose M, et al. Clinical presentation, diagnosis and management of aerodigestive tract foreign bodies in the adult population: part 1. SA J Radiol. 2021;25:2022. doi:10.4102/ sajr.v25i1.2022

4. Geng C, Li X, Luo R, et al. Endoscopic management of foreign bodies in the upper gastrointestinal tract: a retrospective study of 1294 cases. Scand J Gastroenterol. 2017;52(11):1286-1291. doi:10.1080/00365521.2017.1350284

5. Yuan F, Tang X, Gong W, et al. Endoscopic management of foreign bodies in the upper gastrointestinal tract: an analysis of 846 cases in China. Exp Ther Med. 2018;15(2):1257-1262. doi:10.3892/ etm.2017.5561

6. Ikenberry S, Ikenberry SO, Jue TL, et al. Management of ingested foreign bodies and food impactions. Gastrointest Endosc. 2011;73 (6):1085-1091. doi:10.1016/j.gie.2010.11.010

7. Lin J, Fang J, Wang D, et al. Chinese expert consensus on the endoscopic management of foreign bodies in the upper gastrointestinal tract (2015, Shanghai, china). J Dig Dis. 2016;17(2):65-78. doi:10.1111/1751-2980.12318

8. Birk M, Bauerfeind P, Deprez P, et al. Removal of foreign bodies in the upper gastrointestinal tract in adults: European Society of Gastrointestinal Endoscopy (ESGE) clinical guideline. Endoscopy. 2016;48(5):489-496. doi:10.1055/s-0042-100456

9. Li Z, Sun Z, Zou D, et al. Endoscopic management of foreign bodies in the upper-GI tract: experience with 1088 cases in China. Gastrointest Endosc. 2006;64(4):485-492. doi:10.1016/j.gie.2006.01.059

10. Ragazzi M, Delcò F, Rodoni-Cassis P, et al. Toothpick ingestion causing duodenal perforation. Pediatr Emerg Care. 2010;26 (7):506-507. doi:10.1097/PEC.0b013e3181e5bf85

11. Murakami D, Harada H, Amano Y. Fish bone perforation of the duodenum. Ann Gastroenterol. 2020;33:322. doi:10.20524/ aog.2020.0456

12. Webb W. Management of foreign bodies of the upper gastrointestinal tract: update. Gastrointest Endosc. 1995;41(1):39-51. doi:10.1016/ S0016-5107(95)70274-1
13. Simic M, Budakov BM. Fatal upper esophageal hemorrhage caused by a previously ingested chicken bone: case report. Am J Forensic Med Pathol. 1998;19(2):166-168. doi:10.1097/00000433199806000-00013

14. Lee C, Kao B, Wu C, et al. Retrospective analysis of endoscopic management of foreign bodies in the upper gastrointestinal tract of adults. J Chin Med Assoc. 2019;82(2):105-109. doi:10.1097/ JCMA.0000000000000010

15. Yilmaz M, Isik B, Sogutlu G, et al. Duodeno-sigmoid fistula due to ingested metallic wire. J Emerg Med. 2008;34(1):83-84. doi:10.1016/ j.jemermed.2007.06.005

16. Yilmaz M, Akbulut S, Ozdemir F, et al. A swallowed dental prosthesis causing duodenal obstruction in a patient with schizophrenia: description of a new technique. Int J Surg Case Rep. 2012;3 (7):308-310. doi:10.1016/j.ijscr.2012.03.031

17. Skok P, Skok K. Urgent endoscopy in patients with "true foreign bodies" in the upper gastrointestinal tract - a retrospective study of the period 1994-2018. Z Gastroenterol. 2020;58:217-223. doi:10.1055/a-1062-9011

18. Yao CC, Wu IT, Lu LS, et al. Endoscopic management of foreign bodies in the upper gastrointestinal tract of adults. Biomed Res Int. 2015;2015:658602. doi:10.1155/2015/658602

19. Yi L, Cheng Z, Zhou Y, et al. Fishbone foreign body ingestion in duodenal papilla: a cause of abdomina 1 pain resembling gastric ulcer. BMC Gastroenterol. 2020;20:323. doi:10.1186/s12876-02001475-w

20. Opasanon S, Akaraviputh T, Methasate A, et al. Endoscopic management of foreign body in the upper gastrointestinal tract: a tertiary care center experience. J Med Assoc Thai. 2009;92(1):17-21.

21. Steinbach C, Stockmann M, Jara M, et al. Accidentally ingested toothpicks causing severe gastrointestinal injury: a practical guideline for diagnosis and therapy based on 136 case reports. World J Surg. 2014;38(2):371-377. doi:10.1007/s00268-013-2307-z

22. Rajaguru K, Sheong SC. Case report on a rare cause of silent duodenal perforation. Int J Surg Case Rep. 2020;76:320-323. doi:10.1016/j.ijscr.2020.09.184

23. Costa S, Gonçalves R, Rolanda C. Endoscopic removal of multiple sharp gastro-duodenal foreign bodies. Rev Esp Enferm Dig. 2017;109 (2):144-145.

24. Dedania B, Khanapara D, Panwala A, et al. A case of mysterious impacted duodenal foreign body presenting with halitosis. Case Rep Gastroenterol. 2016;10:800-807. doi:10.1159/000454709

25. Wang L, Wen W, Huang J, et al. Endoscopic removal of a duodenal-perforating leg of glasses with dormia basket. Case Rep Gastroenterol. 2016;10:679-684. doi:10.1159/000452205

26. Jadallah K, Alzubi B, Sweidan A, et al. Intraperitoneal duodenal perforation secondary to early migration of biliary stent: closure with through-the-scope clip. BMJ Case Rep. 2019;12(9):e230324. doi:10.1136/bcr-2019-230324

27. Cho EA, Lee Du H, Hong HJ, et al. An unusual case of duodenal perforation caused by a lollipop stick: a case report. Clin Endosc. 2014;47(2):188-191. doi:10.5946/ce.2014.47.2.188

28. Shishido T, Oka S, Tanaka S, et al. Removal of a sewing needle penetrating the wall of the third portion of the duodenum by double-balloon endoscopy. Clin J Gastroenterol. 2012;5:79-81. doi:10.1007/s12328-011-0274-1

29. Cheng NM, Yip HC, Chan SM, et al. Endoscopic removal of a submucosal embedded foreign body in the duodenum. Endoscopy. 2020;52(10):E353-E354. doi:10.1055/a-1122-8240

30. Guo YN, Li F, Huang F, et al. Endoscopic removal of a large foreign body retained in the duodenum: a case report. Medicine. 2020;99: e20857. doi:10.1097/MD.0000000000020857

31. Chaves D, Ishioka S, Félix V, et al. Removal of a foreign body from the upper gastrointestinal tract with a flexible endoscope: a prospective study. Endoscopy. 2004;36(10):887-892. doi:10.1055/ s-2004-825856 
32. Li Voti G, Di Pace M, Castagnetti M, et al. Needle perforation of the bowel in childhood. $J$ Pediatr Surg. 2004;39(2):231-232. doi:10.1016/j.jpedsurg.2003.10.017

33. Wu C, Khan N, Yuan X, et al. Duodenal perforation caused by iron bar. Am J Gastroenterol. 2018;113(10):1429. doi:10.1038/s41395-018-0263-9

34. Robert B, Bartoli E, Fumery M, et al. Duodenal perforation due to toothpick perforation, an uncommon cause of chronic abdominal pain. Endoscopy. 2012;44(S 02):E27-E28. doi:10.1055/s-00311291507

35. Hsieh M, Lee T, Tseng C, et al. Duodenum-penetrating toothpick with liver abscess: removal with single-balloon enteroscopy. Endoscopy. 2011;43(S 02):E11-E12. doi:10.1055/s-0030-1255816

36. Turaihi H, Assam J, Zanfes J, et al. Laparoscopic treatment of a pyogenic hepatic abscess caused by transmural duodenal perforation of a toothpick. $S$ D Med. 2017;70(8):369-371.

37. Jimenez-Fuertes M, Moreno-Posadas A, Ruíz-Tovar Polo J, et al. Liver abscess secondary to duodenal perforation by fishbone: report of a case. Rev Esp Enferm Dig. 2016;108(1):42.

38. Goh B, Chow P, Quah H, et al. Perforation of the gastrointestinal tract secondary to ingestion of foreign bodies. World J Surg. 2006;30 (3):372-377. doi:10.1007/s00268-005-0490-2
39. Shiu-cheung chan S, Russell M, Ho-Fung VM. Not all radiopaque foreign bodies shadow on ultrasound: unexpected sonographic appearance of a radiopaque magnet. Ultrasound Q. 2014;30 (4):306-309. doi:10.1097/RUQ.0000000000000071

40. Wang Z, Du Z, Zhou X, et al. Misdiagnosis of peripheral abscess caused by duodenal foreign body: a case report and literature review. BMC Gastroenterol. 2020;20(1):236. doi:10.1186/s12876-02001335-7

41. Zhang S, Wang J, Wang J, et al. Transparent cap-assisted endoscopic management of foreign bodies in the upper esophagus: a randomized, controlled trial. J Gastroenterol Hepatol. 2013;28(8):1339-1342. doi:10.1111/jgh.12215

42. Tan LN, Tan YY, Liu DL. Successfully endoscopic retrieval of ingested toothpicks in colorectum: a report of four cases. Acta Gastroenterol Belg. 2020;83(2):319-321.

43. Islam S, Islam E, Hodges D, et al. Endoscopic removal of multiple duodenum foreign bodies: an unusual occurrence. World $J$ Gastrointest Endosc. 2010;2(5):186-189. doi:10.4253/wjge.v2. i5.186
International Journal of General Medicine

\section{Publish your work in this journal}

The International Journal of General Medicine is an international, peer-reviewed open-access journal that focuses on general and internal medicine, pathogenesis, epidemiology, diagnosis, monitoring and treatment protocols. The journal is characterized by the rapid reporting of reviews, original research and clinical studies
Dovepress

across all disease areas. The manuscript management system is completely online and includes a very quick and fair peer-review system, which is all easy to use. Visit http://www.dovepress.com/ testimonials.php to read real quotes from published authors. 